\title{
Changes in life satisfaction when losing one's spouse: individual differences in anticipation, reaction, adaptation and longevity in the German Socio-economic Panel Study (SOEP)
}

\author{
FRANK J. INFURNA*, MAJA WIEST $\uparrow$, DENIS GERSTORF $\ddagger \S \|$, \\ NILAM RAM§\|I, JÜRGEN SCHUPP\$**, GERT G. WAGNER $\$ \uparrow \dagger$ \\ and JUTTA HECKHAUSEN+t
}

\begin{abstract}
Losing a spouse is among the most devastating events that may occur in people's lives. We use longitudinal data from 1,224 participants in the German Socio-economic Panel Study (SOEP) to examine (a) how life satisfaction changes with the experience of spousal loss; (b) whether socio-demographic factors and social and health resources moderate spousal loss-related changes in life satisfaction; and (c) whether extent of anticipation, reaction and adaptation to spousal loss are associated with mortality. Results reveal that life satisfaction shows anticipatory declines about two and a half years prior to (anticipation), steep declines in the months surrounding (reaction) and lower levels after spousal loss (adaptation). Older age was associated with steeper anticipatory declines, but less steep reactive declines. Additionally, younger age, better health, social participation and poorer partner health were associated with better adaptation. Higher pre-loss life satisfaction, less steep reactive declines and better adaptation were associated with longevity. The discussion focuses on the utility of examining the interrelatedness among anticipation, reaction and adaptation to further our understanding of change in life satisfaction in the context of major life events.
\end{abstract}

$\boldsymbol{K E Y} \boldsymbol{W O R D S}$ - anticipation of major life events, bereavement, hedonic treadmill, subjective wellbeing, German Socio-economic Panel Study, SOEP.

* Arizona State University, Tempe, USA.

$\dagger$ Evangelische Hochschule (EHB), Berlin, Germany.

† Humboldt University Berlin, Germany.

$\S$ German Institute for Economic Research (DIW Berlin), Germany.

II Pennsylvania State University, University Park, USA.

If Max Planck Institute for Human Development, Berlin, Germany.

** Free University, Berlin, Germany.

t† Berlin University of Technology (TUB), Berlin, Germany.

t+ University of California, Irvine, USA. 


\section{Introduction}

Spousal loss is among those major life events that may shape individuals' developmental trajectories (Baltes and Nesselroade 1979; Diener, Lucas and Scollon 20o6; Holmes and Rahe 1967). Spousal loss is a relatively common phenomenon, particularly for women in old age. For example, in the United States of America some 13 million Americans are widowed at any given time (Elliott and Simmons 2011) and in Germany 57 per cent of individuals aged 80 and older are widowed (Noll, Habich and Schupp 2008). Several studies convincingly demonstrated that losing a spouse is, on average, associated with dramatic declines in life satisfaction (Bonanno et al. 2002; Lee and DeMaris 2007; Lucas et al. 2003; Ong, Fuller-Rowell and Bonanno 2010) and is predictive of physical health declines and earlier death (Elwert and Christakis 2008; Schulz and Beach 1999; Stroebe, Schut and Stroebe 2007). Although the majority of people appear to be able to adjust to the loss, there are substantial individual differences in the extent to which individuals adapt to spousal loss (Bonanno 2004; Carr and Utz 2002; Infurna and Luthar in press).

Our study seeks to advance insight into the effects of spousal loss in three ways. First, we explore the specific time-course of changes in life satisfaction in relation to spousal loss. Second, we examine how socio-demographic factors as well as social and health resources moderate changes in life satisfaction in relation to spousal loss. Third, we examine the unique and shared predictive effects of spousal loss-related changes in life satisfaction on mortality. To do so, we capitalise on the strengths of longitudinal data from a subset of bereaved participants in the German Socio-economic Panel (SOEP) - a widely used long-running panel study that covers the full age range of adulthood.

\section{Change in life satisfaction with spousal loss}

In the larger context of psychological research on life satisfaction, the hedonic treadmill model (Brickman and Campbell 1971) has emerged as an overarching model to examine whether major life events, such as spousal loss, influence changes in wellbeing in adulthood and old age. The hedonic treadmill model postulates that event-related changes in wellbeing encompass reaction and adaptation (Diener, Lucas and Scollon 2006; Frederick and Loewenstein 1999; Lucas 2007a). Empirical reports focusing on spousal loss are largely consistent with a distinction between reaction and adaptation. For example, Lucas et al. (2003) found that individuals typically exhibit sharp declines in life satisfaction in the year surrounding spousal loss (reaction; -o.86 standard deviation (SD)), with individuals 
typically reporting sustained lower levels of life satisfaction following spousal loss and evidence to suggest that life satisfaction takes up to eight years to return back to pre-loss levels (adaptation). Similar results have been observed with other facets of subjective wellbeing, such as depressive symptoms, anxiety, as well as positive and negative affect (Carr et al. 2000; Lee and DeMaris 2007; Wade and Pevalin 2004). For example, Ong, Fuller-Rowell and Bonanno (2010) observed that compared to a matched control group, individuals who experienced spousal loss exhibited significant declines in positive emotions across a three-year period following spousal loss.

Conceptual models and empirical research on spousal loss and bereavement suggest that changes in functioning as a result of losing a spouse may be observable before the loss and may involve a certain extent of anticipation. The major approaches in this area agree that the months or years prior to the spousal loss are characterised by pre-emptive changes (anticipation; see Glaser and Strauss 1968; Kastenbaum and Costa 1977), followed by mourning and grief in the time surrounding spousal loss (reaction), and culminating in a transformation involving both disengagement and connection (adaptation; Boerner and Heckhausen 2003). There are typically substantial between-person differences in such changes (Wortman and Boerner 2007; Bonanno 2004; Infurna and Luthar in press; Wortman and Silver 1989), with empirical evidence suggesting gender differences in the ramifications of widowhood, which are typically the result of differences in the availability of resources (see Stevens 1995). For example, men are more likely to show more profound declines in psychological wellbeing (see Carr 2004; Naess, Blekesaune and Jakobsson 2015; Williams 2003), with possible explanations including men's dependence on their wives for emotional support and the maintenance of social contacts with others and women's generally stronger support networks (see Lee and DeMaris 2007). We aim to integrate and substantiate these conceptual models by directly modelling the specific time-course of changes in life satisfaction through hypothesised stages (e.g. anticipation, reaction and adaptation), which promises to go above and beyond previous research that has solely focused on modelling the reaction and adaptation (Lucas et al. 2003).

Initial empirical evidence suggests that individuals may show declines from baseline levels of wellbeing prior to spousal loss (Kastenbaum and Costa 1977; Lichtenstein et al. 1996; Ong, Fuller-Rowell and Bonanno 2010), but this research has been limited to only one or two observations before spousal loss. In the present study, we aim to explore the existence of pre-emptive changes in life satisfaction that we characterise as anticipatory. The anticipatory period signifies the process of changes in life satisfaction (declines or stability) preceding spousal loss that may begin months or even years prior to the death event (Carr and Utz 2002). One would expect 
large between-person differences in the timing of the anticipatory period, ranging from several years before losing one's spouse (e.g. when dealing with a long-term illness of the spouse) to no anticipatory changes at all. In particular, we propose that anticipation could reflect either an adaptive process of proactive coping or a compromising process of resource depletion. Regarding anticipation as a proactive process, individuals may adjust their goals and disengage from goals associated with the spouses survival (Boerner and Heckhausen 2003; Haase, Heckhausen and Wrosch 2013; Heckhausen, Wrosch and Schulz 2010). For example, individuals may recognise that their partner's health is deteriorating and use goal disengagement strategies to distance themselves from unrealistic goals (e.g. an exotic vacation with the spouse; healing the illness) and through goal reengagement select and strive for more attainable goals with the spouse (e.g. spend time together at home; manage the pain) and goals in other domains (e.g. work or own health). This would operate to re-direct one's resources to manage stressful circumstances more effectively (Wrosch, Amir and Miller 2011) and serve an adaptive purpose following spousal loss through less reaction and better recovery. Second, anticipatory changes could be the result of individuals having few resources in the social, psychological and health domains that protect against decrements due to spousal loss (e.g. vulnerability; Charles 2010). Stressors and burdens associated with possible care-giving responsibilities may constrain one's emotion regulation capacities (Aneshenshel, Botticello and YamamotoMitani 1995; Charles 2010), resulting in lower levels and declines in life satisfaction preceding spousal loss.

\section{Timing of spousal loss-related change in life satisfaction}

What is largely lacking in current research on spousal loss is the specification of the duration and the interrelatedness of change patterns such as anticipation, reaction and adaptation. The timing and measurement of observations may play a role in examining the patterning of change in life satisfaction before and after spousal loss. Recent research shows that the specificity of the time metric (e.g. months versus years) may impact the amount of change that is observed empirically. For example, Uglanova and Staudinger (2013) observed that using granular time intervals (i.e. yearly) may mask the change that accompanies negative life events and that analyses based on three-month intervals provided additional specificity for examinations of change in life satisfaction in relation to major life events (see also Frijters, Johnston and Shields 2011 ).

To attain greater specificity in the timing and interrelatedness of anticipation, reaction and adaptation, we apply latent basis growth models 
(see McArdle 2009; Ram and Grimm 2007) to longitudinal data from the SOEP (Headey, Muffels and Wagner 2010; Wagner, Frick and Schupp 2007). Latent basis growth models permit description of and better articulation of non-linear patterns of change in each hypothesised stage (see Burke, Shrout and Bolger 2007) and examinination of whether there are between-person differences in those non-linear patterns of change. This will be done by isolating the observations for each stage and estimating each stage using latent basis parameters and including factors to examine whether they moderate such changes (see Myrskylä and Margolis 2014). Rather than imposing a specific functional form on the shape of change, the algorithm quantifies the pattern of change to emerge from the raw data (more details are given in the methods section; for application at other time scales, see Fortunato, Gatzke-Kopp and Ram 2013).

\section{Individual differences in change in life satisfaction with spousal loss}

Research has repeatedly demonstrated that there are large between-person differences in how individuals anticipate, react and adapt to life-altering events (Boerner and Wortman 2007; Wortman and Silver 1989; Zautra et al. 2008). Spousal loss represents one of life's significant adversities that can have substantial effects on many areas of life and tremendous individual variability in these effects, with some individuals succumbing and showing declines in functioning, whereas others being resilient and able to recover from adversity (e.g. Bonanno 2004; Netuveli et al. 2008). The evidence is mixed as to the degree to which individuals are able to adapt or recover from spousal loss. The research on resilience most often uses measures of distress and mental health and shows that the majority do not develop mental health problems. Initial research showed that most individuals are resilient, by showing stable, high levels of wellbeing (see Mancini, Bonanno and Clark 2011). However, more recent research suggests that most individuals show profound declines in wellbeing and mental health, but are able to recover or (almost) return back to previous levels of functioning (i.e. recovery; see Infurna and Luthar in press; Stone, Evandrou and Falkingham 2013; Wade and Pevalin 2004). Following conceptual notions of resilience that various factors are likely independent predictors of better functioning following spousal loss and to understand the heterogeneity of individual change in life satisfaction surrounding spousal loss, we examine whether socio-demographic factors and social and health resources moderate the extent of changes within anticipation, reaction and adaptation. In times of great life distress, people typically draw upon resources to help protect against losses in domains, such as life satisfaction, and these resources may operate differently during the various stages. Social 
resources include one's social network integration and the quality of social relationships (Aldao 2013; Antonucci 2001). Health resources broadly include presence of chronic illness, functional limitations and self-perceptions of health, as well as spousal health. Furthermore, socio-demographic factors likely moderate change in life satisfaction with spousal loss and will also be a focus in this study.

Anticipation. We hypothesise that age, participant health status and spousal health will likely moderate changes in life satisfaction during anticipation. Older age may result in an anticipatory period that involves strong declines in life satisfaction preceding spousal loss. Very old adults may have fewer resources to draw upon to mitigate new burdens encountered with widowhood (e.g. losses in key domains of cognitive, physical and social functions; Gerstorf, Smith and Baltes 2006; Jopp and Smith 2006). Furthermore, individuals who suffer from disabling conditions often report poor life satisfaction, presumably as a result of already challenged self-regulatory capacities (Charles 2010; Infurna et al. 2011; Lucas 2007b) that would be further taxed by spousal loss. Functional limitations of the partner may increase the risk of providing assistance and care on a regular basis, which could make death more likely and thus predictable, resulting in anticipatory declines.

Reaction. We hypothesise that age, gender, social resources and spousal health will have the most salient moderating effect on reaction. Experiencing spousal loss in young adulthood or mid-life may result in larger decrements in life satisfaction because more joint time is lost and it is an unexpected and off-time event (Neugarten and Hagestad 1976). In a similar vein, older adults may be better at accepting their partners and one's own worsening health and death and, therefore, are less likely to experience declines in life satisfaction. Research on gender differences in bereavement-related change in life satisfaction suggests that women report stronger increases in depressive symptoms in the years surrounding spousal loss (Carr 2004; Lee and DeMaris 2007). Social resources, such as social network integration and supportive relationships, may protect against the negative impact of losing a spouse; a social network that involves more supportive, emotionally meaningful relationships with a larger pool of individuals to go to, to help cope and protect against declines in life satisfaction (Bonanno 2004; Stroebe et al. 2005). Spousal health is viewed as a proxy for the surviving spouse to possibly be involved in a care-giving role due to a disability or chronic illness of their loved one. The care-giving literature shows that placement and passing of the care recipient oftentimes results in event-related increases in the care-giver's life satisfaction and other pertinent psychological resources due to absence of care-giving-related duties and 
decreases in care-giver burden (Gaugler, Pot and Zarit 2007; Schulz et al. 2003, 2004).

Adaptation. We postulate that gender, education, social resources and health resources will serve a vital role in providing individuals with the opportunity to recover following spousal loss. Men have been found to report more profound declines in psychological wellbeing (see Carr 2004; Naess, Blekesaune and Jakobsson 2015; Williams 2003), which could be due to women being better integrated and having more supportive social relationships beyond the spousal bond. More educated people may be more likely to return back to their previous levels of functioning because they tend to know and use more adaptive and compensatory strategies (Adler et al. 1994). For example, educational attainment is associated with psycho-social resources of perceived control that individuals can utilise in stressful contexts to buffer against declines in life satisfaction (Aneshensel, Botticello and Yamatoto-Mitani 2004; Lachman and Weaver 1998). Social integration and having supportive social relationships may help individuals find comfort in being with others, resulting in improvements in life satisfaction following spousal loss (Bisconti, Bergeman and Boker 2006; Stroebe et al. 2005). For example, social support may buffer against adverse physiological processes that underlie lower levels of life satisfaction (Stroebe et al. 1996). Poorer individual health may limit one's ability to adapt and recover one's life satisfaction (Wiest et al. forthcoming), whereas poor spousal health may lead to quicker recovery or adaptation due to a greater expectation of spousal loss (Bonanno et al. 2002).

\section{Mortality following spousal loss}

Spousal loss often has long-term health implications (Schulz and Beach 1999; Stroebe, Schut and Stroebe 2007), including increased mortality (Elwert and Christakis 2006; Roelfs et al. 2012; Stroebe, Schut and Stroebe 2007). We examine whether life satisfaction levels and changes preceding (anticipation), surrounding (reaction) and following (adaptation) spousal loss are associated with mortality. Previous research suggests that both levels of and changes in various personality and psychological factors can have health consequences (Infurna, Ram and Gerstorf 2013; Mroczek and Spiro 2007; Zhang et al. 2009).

Levels of life satisfaction prior to spousal loss are a proxy for better overall functioning across domains, including health (Pressman and Cohen 2005). Similar to previous research from panel surveys, we would expect that higher levels of life satisfaction prior to spousal loss promote longevity (Danner et al. 2001; Wiest et al. 2011; Zhang et al. 2009). Declines in life 
satisfaction that precede spousal loss (i.e. anticipatory changes) may provide a protective function for mortality through prompting individuals to partake in adaptive and coping strategies to maintain one's health following spousal loss (Heckhausen, Wrosch and Schulz 2010). Conversely, anticipatory declines may be a proxy for poorer underlying health, resulting in an increased likelihood of mortality following spousal loss. Too steep declines in life satisfaction with spousal loss (reaction) may have serious consequences for everyday functioning and living (Lyubormirsky et al. 2005). Conversely, no changes in life satisfaction surrounding spousal loss could be a sign of low emotional flexibility, which can have negative health consequences as well (Carstensen et al. 2011). Following spousal loss, sustained lower levels of life satisfaction as indexed by less/no adaptation may have detrimental effects on health due to its association with health behaviour regulation and biological functioning (Steptoe, Wardle and Marmot 2005; Wiest et al. forthcoming; Williams 2004).

\section{The present study}

Our objective is to examine: (a) how life satisfaction changes with the experience of spousal loss; (b) whether socio-demographic factors and social and health resources moderate spousal loss-related changes in life satisfaction; and (c) whether the extent of anticipation, reaction and adaptation to spousal loss are associated with mortality. We first expect that changes during the months and years preceding spousal loss will reflect an anticipation period (years -5 to -1 prior to spousal loss), characterised by declines in life satisfaction. Furthermore, based on previous evidence (see Lucas et al. 2003), we expect that individuals, on average, will experience steep declines in life satisfaction in the months surrounding spousal loss (reaction), but will (almost) return back to previous levels in the years following (adaptation; years $1-5$ following spousal loss). Second, focusing on between-person differences and factors that moderate change in life satisfaction with spousal loss, we hypothesise that socio-demographic factors and social and health resources will serve different functions during anticipation, reaction and adaptation. Third, we expect that higher levels of life satisfaction prior to spousal loss and greater ability to adapt will be associated with longevity.

\section{Method}

We examined these hypotheses using data from 28 waves $\left(1984^{-2011}\right)$ of the SOEP (Headey, Muffels and Wagner 2010). Comprehensive information about the design, participants, variables and assessment procedures 
in the study is reported in Wagner, Frick and Schupp (2007). Details relevant to the present analysis are given below.

\section{Participants and procedure}

The SOEP is a nationally representative annual panel study of private households and their inhabitants initiated in 1984. The SOEP covers approximately 50,00o residents of Germany, including immigrants and resident foreigners. Potential participants were randomly selected from a set of randomly selected locations in Germany. Within each household, all family members older than 16 years of age were eligible for personal participation. Relatively high initial response rates (between 6o and $70 \%$ ) and low longitudinal attrition (about $15 \%$ for the second wave and less than $5 \%$ yearly attrition across various sub-samples) provide for an overall sample that is representative of the population living in private households (Kroh et al. 2008). Data were primarily collected via face-to-face interviews and selfadministered mail questionnaires.

For the present study, we analysed data from the 1,224 participants who (a) were married at the outset of the study, (b) had a spouse who also participated in the SOEP, (c) who experienced spousal loss over the course of the study, (d) did not re-marry following spousal loss over the course of the study, and (e) provided data on our measures of interest. Participants in this sub-sample were, on average, 65.35 years of age at spousal loss $(\mathrm{SD}=12.46$, range $\left.25^{-100}\right)$, had attained, on average, 10.74 years of education $(\mathrm{SD}=2.07$, range $7^{-18)}$ and 71 per cent were women. We note that previous research in the SOEP has shown that spousal loss is predictive of sample attrition. Because spousal loss is a predictor of sample attrition, the results obtained can be regarded as conservative tests of our research question. Our results potentially underestimate the amount of wellbeing loss because those who suffer the most are the ones who are most likely to drop out.

\section{Measures}

Life satisfaction. Participants' reported on their life satisfaction annually, answering the question 'How satisfied are you with your life, all things considered?', using a o (totally unsatisfied) to 10 (totally satisfied) rating scale. This item is considered a measure of cognitive-evaluative (as opposed to emotional) aspects of wellbeing and has been used widely in psychological research (for details, see Fujita and Diener 2005; Gerstorf et al. 2008).

Spousal loss. Spousal loss was determined by responses to the question 'Has your family situation changed since the beginning of year $X$ [e.g. 2002]?' in 
the category 'spouse/partner has died'. If the individual indicated that their family situation changed since the beginning of year $X$, then they were asked a follow-up question regarding the month this event occurred. Timing of spousal loss was defined as the month and year the participant reported their spouse/partner died. Spouse/partner month and year of death information was used to re-align yearly reports of life satisfaction in the 6o months prior to and 6o months following spousal loss $-\mathrm{a}$ time period that, theoretically, spans the duration of anticipatory, reactive and adaptive stages. Following procedures applied by Uglanova and Staudinger (2013), we appropriated the monthly data into three-month (quarterly) intervals (e.g. -6 o to $-5^{8}$ months, -57 months to -55 months, and so on). For example, if an observation was at 59 months prior to spousal loss, this was grouped in the -60 to $-5^{8}$ month category. Similarly, changes for the month of spousal loss $\left(\mathrm{LS}_{\mathrm{o}}\right)$ are embedded within the estimated changes associated with $\mathrm{LS}_{\mathrm{o}}$ because this 'window' covers the $\mathrm{o}^{-} 3$ months following spousal loss. Table 1 shows life satisfaction observations 60 months prior to and 60 months following spousal loss and the average score for life satisfaction. For example, life satisfaction reports were available for $25^{2}$ of 1,224 participants for months -12 to -10 , with the average score being mean $=$ $6.3^{\circ}(\mathrm{SD}=2.07)$. We analysed our data in quarterly intervals as compared to yearly intervals because previous research shows that this time interval (a) provides the most efficient trade-off of sample size and occasions given the incompleteness in the data (i.e. covariance coverage; Uglanova and Staudinger 2013), and (b) maintains the ability to align data with respect to the timing of spousal loss. Participants, on average, provided 8.61 life satisfaction observations $(\mathrm{SD}=1.72$, range $2-11)$ within the 120 months of interest.

Moderators. The socio-demographic and social and health resource variables that were examined as potential moderators of anticipation, reaction and adaptation are shown in Table 2 (along with descriptives). Social participation was measured using a four-item index given regularly in the SOEP that assessed frequency of involvement in or attendance at social networking and community activities, including politics, honorary activities in clubs/ groups, sports and attendance of cultural events (see Headey, Muffels and Wagner 2010; Infurna et al. 2011). The scale is highly similar in structure to other instruments used to assess social participation (see Parslow et al. 2006). Participants answered each item on a scale from 1 (each week) to 4 (never). Responses were reverse coded and averaged to obtain an index with higher scores indicating greater social participation. Repeated observations of an individual's social participation obtained in the available period prior to spousal loss were averaged, so that social participation scores 
T A в L E 1. Descriptive statistics for life satisfaction in relation to spousal loss

\begin{tabular}{|c|c|c|c|c|}
\hline & $\begin{array}{l}\text { Time to/from spousal } \\
\text { loss (months) }\end{array}$ & Number of observations & Mean & SD \\
\hline \multirow[t]{3}{*}{ Level } & $-6 o$ to $-5^{8}$ & 209 & 6.74 & 2.01 \\
\hline & -57 to -55 & $25^{2}$ & 7.18 & 1.82 \\
\hline & -54 to $-5^{2}$ & 254 & 7.00 & 1.77 \\
\hline Level & $-5^{1}$ to -49 & 220 & 6.84 & 1.92 \\
\hline \multirow[t]{14}{*}{ Anticipation } & $-4^{8}$ to $-4^{6}$ & 211 & 6.83 & 1.92 \\
\hline & -45 to -43 & 275 & 6.92 & 2.03 \\
\hline & $-4^{2}$ to $-4^{\circ}$ & 247 & 6.96 & 1.92 \\
\hline & -39 to -37 & 249 & 6.90 & 1.99 \\
\hline & $-3^{6}$ to -34 & 276 & 6.93 & 1.88 \\
\hline & -33 to -31 & 278 & 6.99 & $1.9^{\circ}$ \\
\hline & -30 to -28 & 266 & 6.83 & 1.87 \\
\hline & -27 to -25 & 304 & $6.7^{6}$ & 2.01 \\
\hline & -24 to -22 & 260 & 6.54 & 2.15 \\
\hline & -21 to -19 & $3^{10}$ & 6.84 & 1.97 \\
\hline & -18 to -16 & $3^{14}$ & 6.77 & 1.97 \\
\hline & -15 to -13 & 309 & 6.69 & $1.9^{6}$ \\
\hline & -12 to -10 & $25^{2}$ & 6.30 & 2.07 \\
\hline & -9 to -7 & 335 & 6.57 & 2.07 \\
\hline Anticipation & -6 to -4 & 305 & 6.30 & 2.10 \\
\hline Reaction & -3 to $o$ & 405 & 6.10 & 2.15 \\
\hline Reaction & o to 3 & 328 & $5 \cdot 19$ & 2.31 \\
\hline \multirow[t]{18}{*}{ Adaptation } & 4 to 6 & 330 & $5 \cdot 4^{8}$ & 2.22 \\
\hline & 7 to 9 & 299 & 5.80 & 2.09 \\
\hline & 10 to 12 & 270 & $5 \cdot 74$ & 2.27 \\
\hline & 13 to 15 & 291 & 6.13 & 1.97 \\
\hline & 16 to 18 & 304 & $6.3^{6}$ & 2.13 \\
\hline & 19 to 21 & $25^{\circ}$ & $6.4^{1}$ & 1.89 \\
\hline & 22 to 24 & 249 & $6.3^{8}$ & 1.99 \\
\hline & 25 to 27 & 288 & 6.39 & 2.02 \\
\hline & 28 to 30 & 265 & 6.54 & 2.01 \\
\hline & $3^{1}$ to 33 & 227 & 6.36 & 1.75 \\
\hline & 34 to $3^{6}$ & 259 & 6.71 & 1.88 \\
\hline & 37 to 39 & 237 & 6.74 & $1.8 \mathrm{o}$ \\
\hline & $4^{\mathrm{O}}$ to $4^{2}$ & $25^{2}$ & 6.55 & 2.02 \\
\hline & 43 to 45 & 208 & 6.64 & 1.94 \\
\hline & $4^{6}$ to $4^{8}$ & 178 & 6.67 & 1.94 \\
\hline & 49 to $5^{1}$ & 216 & 6.55 & 2.03 \\
\hline & $5^{2}$ to 54 & 226 & 6.57 & 1.88 \\
\hline & 55 to 57 & 169 & 6.88 & 1.87 \\
\hline Adaptation & $5^{8}$ to 60 & 160 & 6.94 & 1.68 \\
\hline
\end{tabular}

Notes: N = 1,224 participants provided 10,537 observations. Participants, on average, provided 8.61 (standard deviation $(\mathrm{SD})=1.72$, range $2-11$ ) life satisfaction observations over this time period. The number of observations column refers to the number of life satisfaction observations we have for this time period in the study across the participants. The mean column refers to the average score of life satisfaction, based on a $\mathrm{o}-10$ scale, during that time period in the study in relation to spousal loss. The SD column refers to the SD or distribution of scores for life satisfaction during that time period in the study in relation to spousal loss. For example, for months -12 to -10 , we have $25^{2}$ life satisfaction observations out of the 1,224 participants who were included in this study, the average score at this time period is 6.30 , with $\mathrm{SD}=2.07$. 
T A в L E 2. Means, standard deviations (SD) and intercorrelations among moderators included in the present study

\begin{tabular}{|c|c|c|c|c|c|c|c|c|}
\hline & Mean & SD & 1 & 2 & 3 & 4 & 5 & 6 \\
\hline 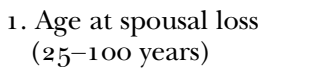 & $65 \cdot 35$ & $12.4^{6}$ & - & & & & & \\
\hline 2. Women (\%) & 0.71 & 0.45 & $-0.08^{*}$ & - & & & & \\
\hline 3. Education ( $7-18$ years) & 10.74 & 2.07 & $-0.09 *$ & $-0.18 *$ & - & & & \\
\hline $\begin{array}{l}\text { 4. Social participation } \\
(1-4)\end{array}$ & $1.4^{\mathrm{O}}$ & 0.44 & -0.14 & $-0.12^{*}$ & $0.3^{*}$ & - & & \\
\hline $\begin{array}{l}\text { 5. Disability: individual } \\
(1=\text { disabled })\end{array}$ & $0.3^{8}$ & 0.49 & $0.14^{*}$ & $-0.14^{*}$ & $-0.09^{*}$ & -0.04 & - & \\
\hline $\begin{array}{l}\text { 6. Disability: partner } \\
(1=\text { disabled })\end{array}$ & $0.5^{2}$ & $0.5^{0}$ & $0.09^{*}$ & $0.08^{*}$ & $-0.07^{*}$ & $-0.07^{*}$ & $0.12 *$ & - \\
\hline
\end{tabular}

Note: $\mathrm{N}=1,224$ (353 men, 871 women).

Significance level: * $p<0.05$.

indicate the level of social resources individuals bring to spousal loss. Disability status of both the individual and the spouse were derived from a single item asking each year whether the respondent was 'officially certified as having a reduced capacity to work or being severely handicapped' (for details, see Infurna et al. 2011 ; Lucas 2007b). Thus, disability indicators were based on self-reports, but referred to official certifications. These repeated assessments were used as a time-invariant measure that indicates whether the individual or spouse was disabled at any point prior to spousal loss. In follow-up analyses, the pattern of findings did not differ when we included the length of disability prior to spousal loss or whether the person of focus became disabled during the five years (6o months) prior to spousal loss as a moderator. Of the 1,224 individuals who experienced spousal loss in our sample, $75^{8}$ were not disabled and 466 were disabled prior to spousal loss. Of the 1,224 spouses who died, 593 were not disabled and 631 were disabled prior to death.

Mortality. Mortality status and year of death for deceased participants who lost their spouse was obtained either (a) by interviewers at the yearly assessments (i.e. from household members or, in the case of one-person households, neighbours) or (b) from city registries. Of the 1,224 participants included in our analysis, $324(26 \%)$ have died. On average, deceased participants were 71.36 years of age at the time of spousal loss $(\mathrm{SD}=10.26$, range $31-94)$ and died 8.64 years later $(\mathrm{SD}=5.15$, range $2-24)$. We did not have access to cause of death information and, therefore, our mortality analyses focus on all-cause mortality. Research by Elwert and Christakis (2008) shows that mortality following the event of spousal loss does not vary substantially 


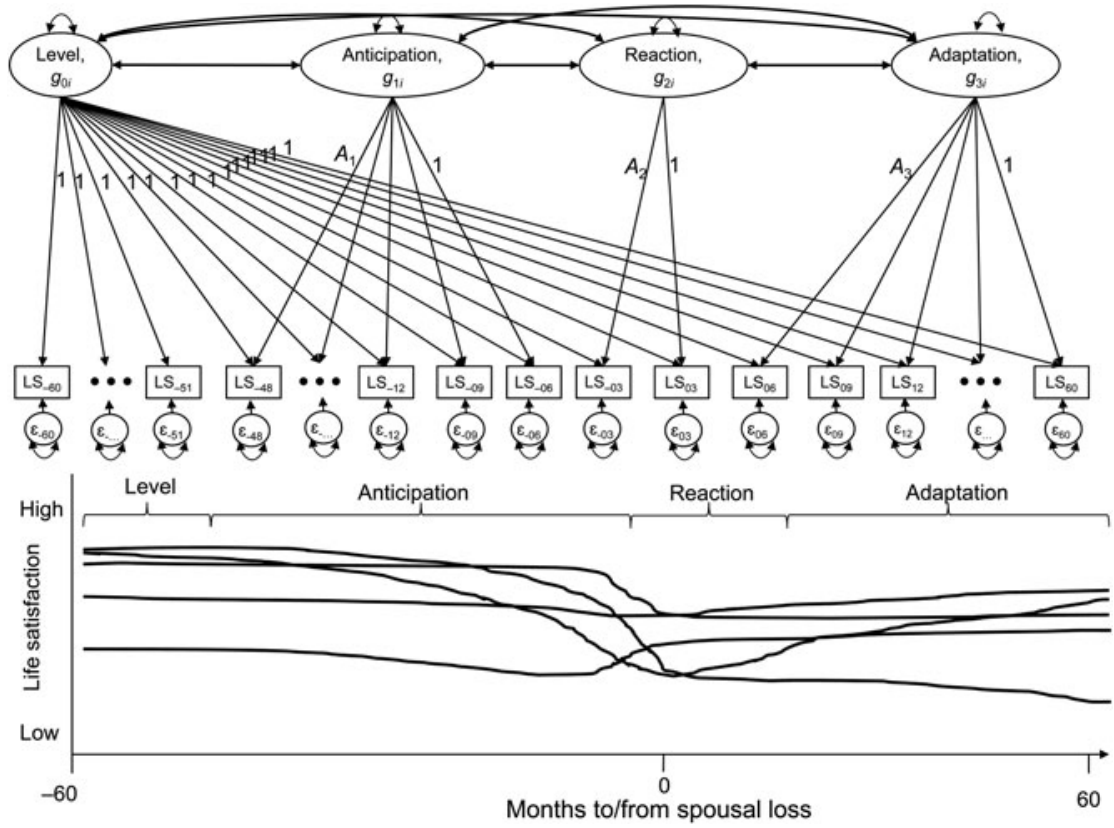

Figure 1. Illustration of the structural equation model (top panel) and components of change that life satisfaction follows in relation to spousal loss. Level components of life satisfaction refer to how individuals may report varying levels of life satisfaction in the several years prior to spousal loss. Anticipation reflects changes in life satisfaction in the years leading up to spousal loss. Reaction refers to how individuals may display differential rates of change with the incidence of spousal loss. Lastly, differential rates of change may be exhibited in the years following spousal loss, which is referred to as adaptation; adaptation may be immediate (one year following spousal loss) or take several years.

Note: Each line in the figure displays a hypothetical trajectory of change for individuals who experience spousal loss. The factor loadings for level are all set to 1. The factor loadings for anticipation, reaction and adaptation that are not labelled 1 are freely estimated. See the text for further explanation of the figure.

by causes of death, suggesting that there is no increased likelihood of one cause of death over another.

\section{Analysis procedures}

Multi-phase latent basis growth model. To examine inter-individual differences in the hypothesised pattern of change, we used a multi-phase latent basis growth model (see Ram and Grimm 2007; Singer and Willet 2003). Figure 1 graphically illustrates the structural equation model that we applied to our data (top panel) and how it maps on to hypothesised spousal loss-related changes in life satisfaction (bottom panel): level (months -60 to -49 ), anticipation (months -48 to -4 ), reaction (months -3 to +3 ) and adaptation (months +4 to +60 ). 
The repeated measures of life satisfaction (rectangles in Figure 1) were modelled as a function of the four latent growth factors (ellipses; level, anticipation, reaction and adaptation) and a set of unique/error factors (circles; assumed to have homogeneous variance). The factor loadings connecting each growth factor to the yearly measures of life satisfaction (arrows connecting ellipses to rectangles) were estimated in a manner similar to confirmatory factor analysis and indicate the shape of the trajectory of life satisfaction (see e.g. Fortunato, Gatzke-Kopp and Ram 2013; Ram and Grimm 2007).

An individual-specific intercept factor score quantifies the expected level of life satisfaction prior to spousal loss, $g_{\mathrm{o} i}$. Anticipation scores $\left(g_{1} i\right)$ and the parameters of the vector $A_{1}[t]$ indicate the extent of change in life satisfaction in the years preceding spousal loss (year -48 months to month -4). Reaction scores $\left(g_{2}\right)$ and the parameters of the vector $A_{2}[t]$ indicate the extent of short-term change in the months surrounding spousal loss (month -3 to month +3 ). Adaptation scores $\left(g_{3} i\right)$ and the parameters of the vector $A_{3}[t]$ indicate the extent of recovery in life satisfaction in the years following spousal loss (month +4 to month +60 ). The factor means (not depicted in figure) describe the level and extent of anticipation, reaction and adaptation for a prototypical widower and the factor variances (small double-headed arrows on each of the ellipses) indicate the extent of between-person differences in each component of the change process.

In subsequent analyses, the models were expanded in two ways. First, to further examine the interrelatedness of the anticipation, reaction and adaptation, we tested a mediation model where the correlations amongst these factors were replaced by regressions. The reaction factor $\left(g_{2}\right)$ was regressed on the anticipation factor $\left(g_{1}\right)$ and the adaptation factor $\left(g_{3}\right)$ was regressed on the anticipation and reaction factors. From the parameters we then determined, using the Sobel test (Sobel 1982), whether reaction mediated the association between anticipation and adaptation. Second, we regressed socio-demographic factors and social and health resources on level $\left(g_{0}\right)$, anticipation $\left(g_{1}\right)$, reaction $\left(g_{2}\right)$ and adaptation $\left(g_{3}\right)$ to examine the extent to which these between-person difference factors moderated each component of the change process.

All models were estimated using MPlus (Muthén and Muthén 2012 ), with incomplete data accommodated under missing at random assumptions at the within-person level, and, to retain longitudinal data, missing completely at random at the between-person level (Little and Rubin 1987; set-ups provided in Ram and Grimm 2007).

Survival analysis. In a final step, we outputted the estimated factor scores from the (unconditional) multi-phase growth model, and used Cox proportional hazard regression models (Cox 1972) to model the hazard for the 
event of mortality in the post-spousal loss period (SAS PROC PHREG; see Allison 1995) as a function of these factor scores, socio-demographic factors, and social and health resource variables.

\section{Results}

\section{Change in life satisfaction with spousal loss}

In a preliminary step, we calculated the intraclass correlation, which was $0.4^{1}$, indicating that $4^{1}$ per cent of the total variance in life satisfaction was between-person variance and 59 per cent was within-person variance. The repeated measures of life satisfaction thus appeared to contain both substantial amounts of between-person differences and within-person variation over time; this suggests that individuals are more likely to differ from themselves over time than their average differs from that of other persons.

Results from the multi-phase latent basis growth model examining changes in life satisfaction in relation to spousal loss are shown in Table 3. Each column displays the latent basis coefficients (i.e. parameters of $A_{k}[t]$ indicate the shape of the trajectory), which specify the proportion of change that has occurred up to that point for each phase of the process: anticipation, reaction and adaptation. Figure 2 shows the modelimplied trajectory of life satisfaction across the study period (black line) for the prototypical participant (average score for each moderator), overlaid on model-implied trajectories for a sub-sample of $5^{\circ}$ participants (grey lines). Life satisfaction was characterised by average levels at months -6 o to $-49\left(\mu_{g o}=7.06, p<0.05\right)$. For anticipation, during the months and years preceding spousal loss (months -48 to -4 ), individuals typically experienced declines in life satisfaction $\left(\mu_{g_{1}}=-0.77, p<0.05, d=-0.43\right)$. The mean of the anticipation factor indicates that during the time interval of -48 months to -4 months prior to spousal loss, the average amount of decline in life satisfaction was -0.77 points on a $\mathrm{o}-10$ scale. For reaction, individuals, on average, experienced a sizeable decrease in life satisfaction in the six months surrounding spousal loss $\left(\mu_{g_{2}}=-1.09, p<0.05, d=-0.60\right)$. The latent basis coefficient for -3 months prior to spousal loss was not reliably different from zero $\left(A_{2}\left[-\mathrm{O}_{3}\right]=0.07\right)$, suggesting that reaction does not occur in the 3 months preceding spousal loss, but only in the three months following spousal loss $A_{2}[+3$ months $\left.]=-1.09\right)$. Following spousal loss, the average pattern of change was characterised by gradual increase post-reaction $\left(A_{3}[t]\right.$ increase from 0.20 at 6 months to 0.98 at 36 months post-loss). However, on average life satisfaction levels did not approach pre-loss levels (baseline level $\mu_{g o}=7.06$ versus level at 60 months 
T А в L 3 . Fixed and random effects and latent basis estimates for examining change in life satisfaction to/from spousal loss

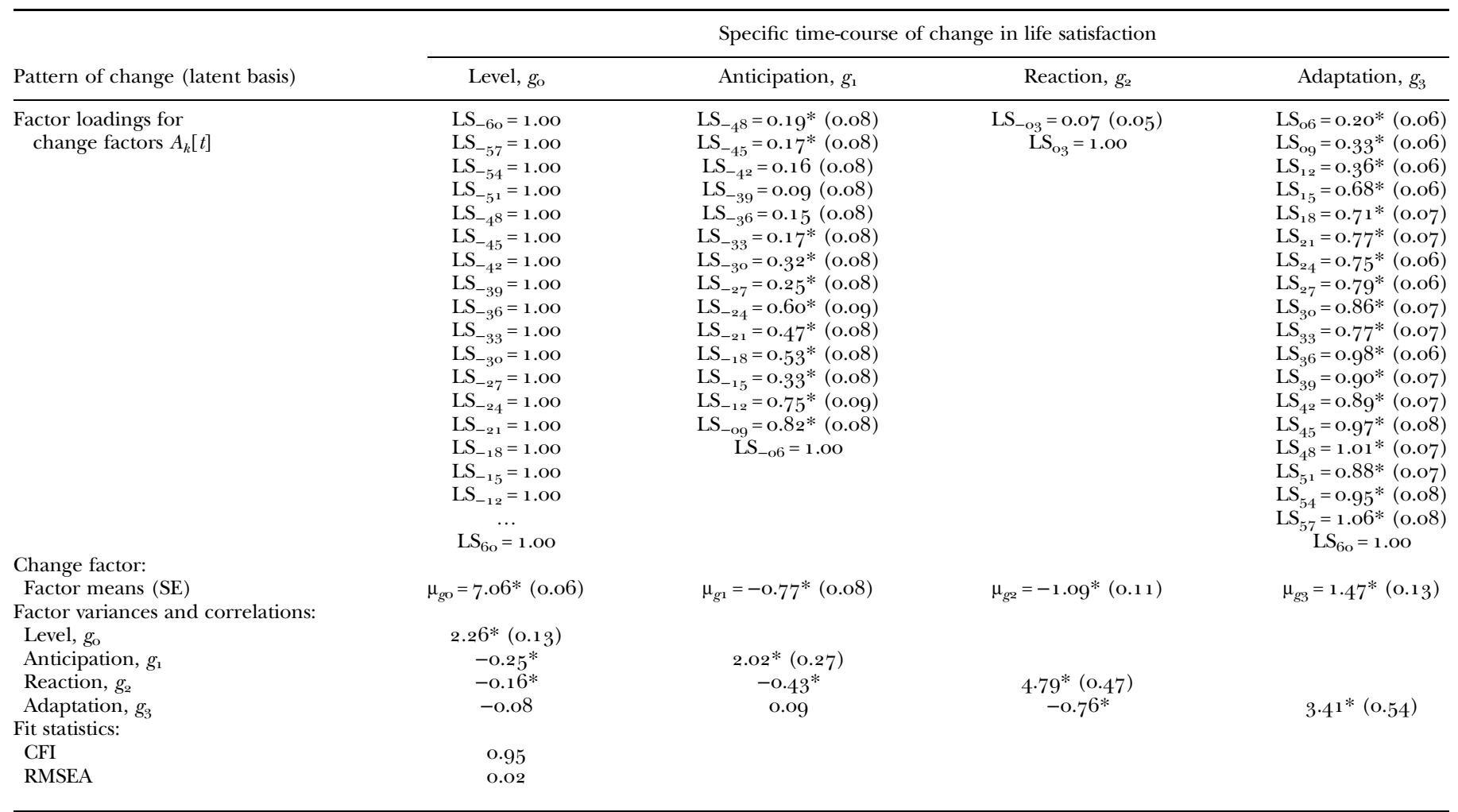

Notes: $\mathrm{N}=1,224$. Number of observations $=10,537$. Residual variance $=1.57$, standard error $(\mathrm{SE})=0.03$. $\mathrm{LS}_{t}=$ life satisfaction observation at $t$ months in relation to spousal loss. Intraclass correlation $=0.4^{1}$. Pseudo-R ${ }^{2}=0.36$. CFI: Comparative Fit Index. RMSEA: Root Mean Square Error of Approximation. The number in parentheses represent the standard errors for the specific parameter.

Significance level: $* p<0.05$. 


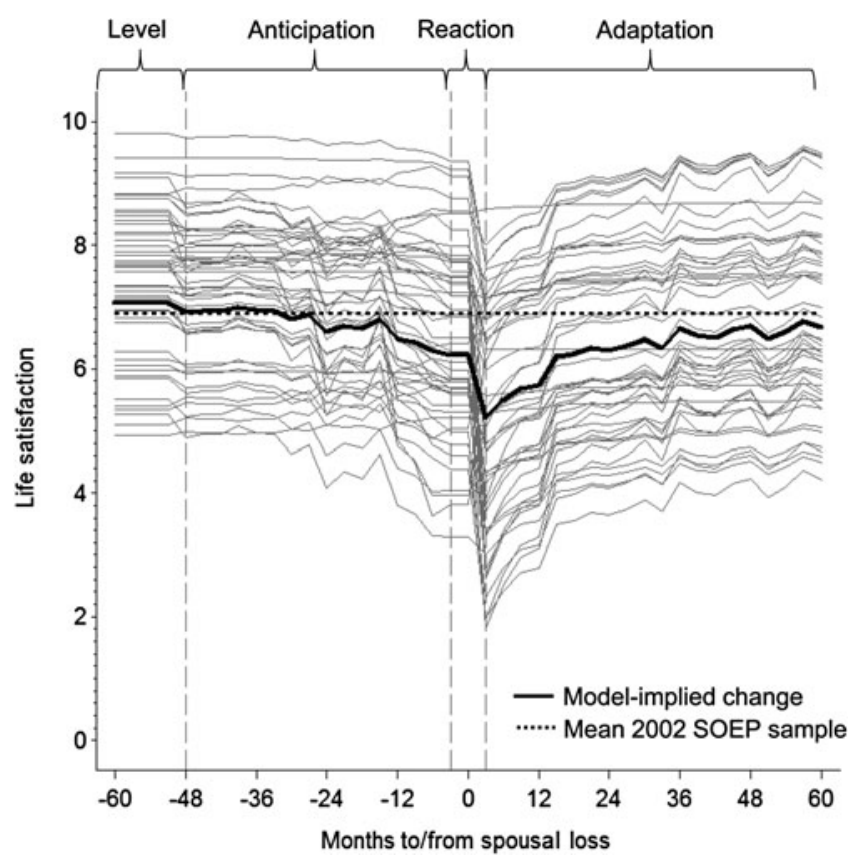

Figure 2. Model-implied mean (black line) for change in life satisfaction in relation to spousal loss with predicted scores from our latent basis model from Table 3 for a sub-sample of $5^{\circ}$ participants (grey lines). Population mean for the 2002 German Socio-economic Panel Study (SOEP) sample is depicted to illustrate how individuals' life satisfaction compares to mean population average. Changes in life satisfaction are characterised by a multi-stage pattern. SOEP participants who experienced spousal loss, on average, reported declines in life satisfaction in the months and years preceding spousal loss (anticipation), substantial declines in the months surrounding spousal loss (reaction) and did not return back to previous levels following spousal loss (adaptation).

post-loss $=6.68,-0.38$ lower, $d=-0.21)$, indicating there is not full recovery (adaptation, $\mu_{g 3}=1.47, p<0.05, d=0.81$ ). This suggests that from three months to five years following spousal loss, life satisfaction went up, on average, 1.47 points, which is still lower than the 1.86 points that it declined from months years prior to spousal loss to three months following spousal loss $\left(\mu_{g_{1}}=-0.77+\mu_{g_{2}}=-1.09=-1.86\right)$.

Finally, the estimated correlations in Table 3 indicate how anticipation, reaction and adaptation were interrelated (in this sample). The correlation of anticipation with reaction and adaptation was $r_{g_{1} g_{2}}=-0.43(p<0.05)$ and $r_{g_{2} g_{3}}=0.09(p>0.05)$, respectively. This suggests that exhibiting stronger anticipatory declines in life satisfaction was associated with less-reactive declines, but was not related to the extent of adaptation. The correlation between reaction and adaptation was $r_{g_{2} g 3}=-0.76(p<0.05)$, suggesting that stronger declines in life satisfaction immediately surrounding the 
spousal loss were associated with more-extensive adaptation. Furthermore, the correlations of level with anticipation, reaction and adaptation were $r_{\text {go } g_{1}}=-0.25(p<0.05), r_{\text {gog } 2}=-0.16(p<0.05)$ and $r_{g 0 g_{3}}=-0.08(p>0.05)$, respectively, suggesting that the level of life satisfaction five years prior to spousal loss was associated with the extent of change during anticipation and reaction, but not during adaptation. Individuals who are at lower levels of life satisfaction at the baseline are less likely to show further declines in life satisfaction with spousal loss, but with no implication for what happens during post-loss recovery.

We tested an additional model that replaced the correlations among anticipation, reaction and adaptation with regressions (i.e. regress reaction on anticipation, regress adaptation on anticipation and reaction). This was done to determine whether reaction mediated the effect of anticipation on adaptation. We found that anticipation predicted reaction $(a=-0.67$, standard error $(\mathrm{SE})=0.10, p<0.01)$, suggesting that stronger declines in life satisfaction during anticipation were associated with less steep declines in reaction. We also found that both anticipation $\left(c^{\prime}=-0.38, \mathrm{SE}=0.07, p<0.01\right)$ and reaction $(b=-0.75, \mathrm{SE}=0.06, p<0.01)$ predicted adaptation, such that stronger declines in life satisfaction during anticipation and reaction were associated with better adaptation or quicker recovery of life satisfaction following spousal loss. The Sobel test confirmed that reaction mediated the effect of anticipation on adaptation (estimate $=5.91, p<0.01$ ).

\section{Individual differences in change in life satisfaction with spousal loss}

With the variance components and predicted trajectories in Figure 2 (grey lines) suggesting that there were meaningful between-person differences in the extent of anticipation $\left(\sigma_{g_{1}}^{2}=2.02, p<0.05\right)$, reaction $\left(\sigma_{g_{2}}^{2}=4.79\right.$, $p<0.05)$ and adaptation $\left(\sigma_{g 3}^{2}=3.41, p<0.05\right)$ to spousal loss, we proceeded to examine whether socio-demographic factors and social and health resources moderated the extent of change. Results are shown in Table 4. Participants who were older $\left(\beta_{11}=-0.02, p<0.05\right)$ were more likely to exhibit declines in life satisfaction preceding spousal loss (anticipation). Participants who were older $\left(\beta_{21}=0.03, p<0.05\right)$ and reported lower levels of social participation $\left(\beta_{24}=-0.70, p<0.05\right)$ were more likely to exhibit less steep declines in life satisfaction in the months surrounding spousal loss (reaction). Lastly, younger age $\left(\beta_{31}=-0.03, p<0.05\right)$, greater social participation $\left(\mu_{34}=0.65, p<0.05\right)$, not being disabled $\left(\mu_{35}=-0.61\right.$, $p<0.05)$ and partner disability $\left(\mu_{36}=-0.36, p<0.05\right)$ were each associated with better adaptation following spousal loss (adaptation). Figure 3 illustrates the age differences, indicating that participants who were older when their spouse died tended to report higher life satisfaction to begin 
$\mathrm{T}$ А $\mathrm{B} \mathrm{L}$ 4. Fixed and random effects and latent basis estimates for examining change in life satisfaction to/from spousal loss: the effect of socio-demographic and social and health resources

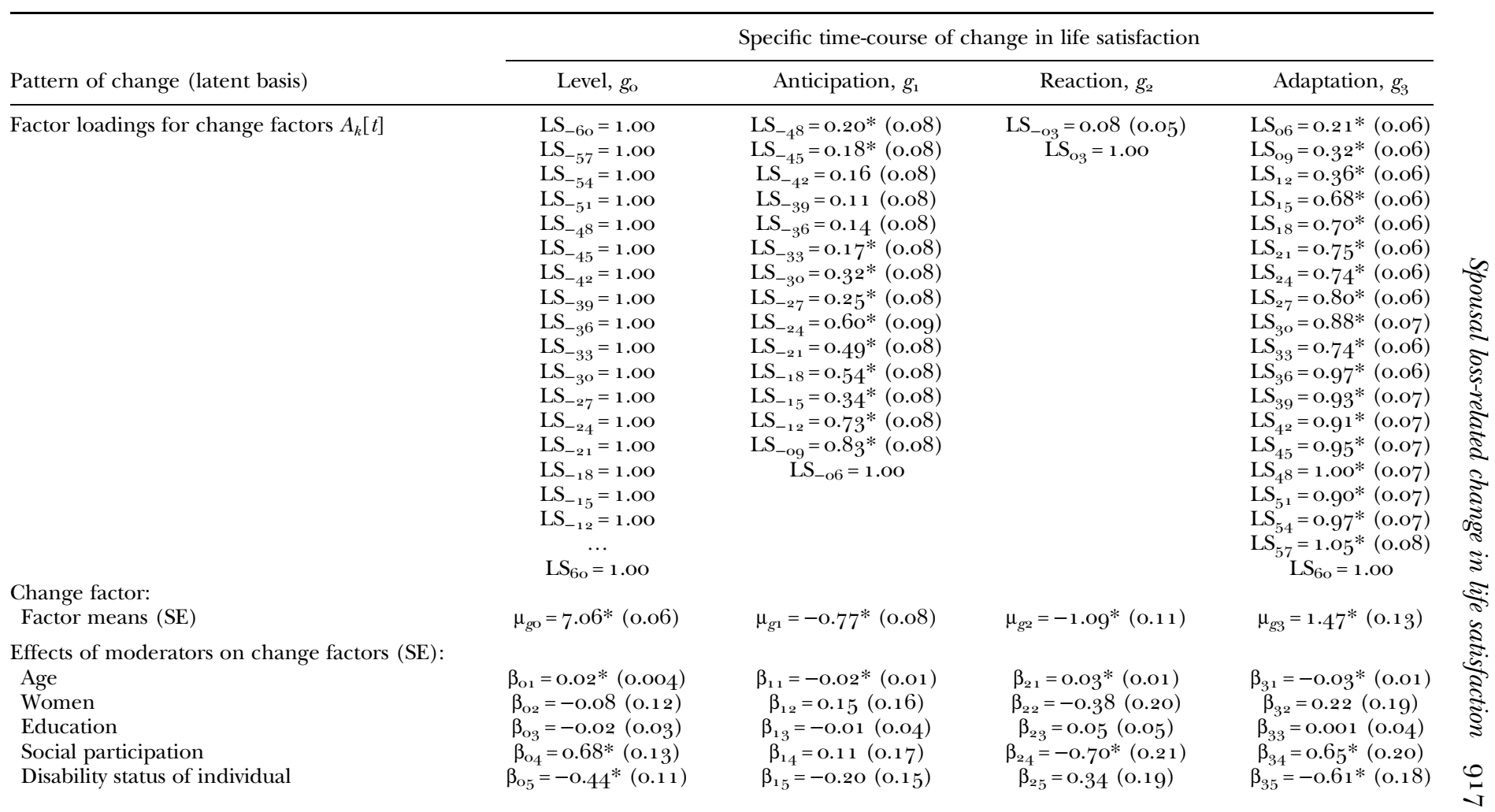


T A B LE $4 \cdot$ ( Cont.)

\begin{tabular}{|c|c|c|c|c|}
\hline \multirow[b]{2}{*}{ Pattern of change (latent basis) } & \multicolumn{4}{|c|}{ Specific time-course of change in life satisfaction } \\
\hline & Level, $g_{0}$ & Anticipation, $g_{1}$ & Reaction, $g_{2}$ & Adaptation, $g_{3}$ \\
\hline Disability status of partner & $\beta_{\mathrm{o} 6}=-0.10(0.10)$ & $\beta_{16}=-0.16(0.14)$ & $\beta_{26}=0.11(0.18)$ & $\beta_{36}=0.36^{*}(0.17)$ \\
\hline \multicolumn{5}{|l|}{ Residual factor variances and correlations: } \\
\hline Level, $g_{\mathrm{o}}$ & $2.09 *(0.13)$ & & & \\
\hline Anticipation, $g_{1}$ & $-0.26^{*}$ & $1.94 *(0.27)$ & & \\
\hline Reaction, $g_{2}$ & $-0.16^{*}$ & $-0.41^{*}$ & $4.49^{*}(0.47)$ & \\
\hline Adaptation, $g_{3}$ & 0.07 & 0.05 & $-0.76^{*}$ & $2.95^{*}(0.54)$ \\
\hline Pseudo $R^{2}$ & 0.075 & 0.040 & 0.063 & 0.135 \\
\hline \multicolumn{5}{|l|}{ Fit statistics: } \\
\hline CFI & 0.94 & & & \\
\hline RMSEA & 0.02 & & & \\
\hline
\end{tabular}

Notes: $N=1,224$. Number of observations $=10,537$. Residual variance $=1.57$, standard error $(\mathrm{SE})=0.03 . \mathrm{LS}_{t}=$ life satisfaction observation at $t$ months in relation to spousal loss. Intraclass correlation = o.41. CFI: Comparative Fit Index. RMSEA: Root Mean Square Error of Approximation. The number in parentheses represent the standard errors for the specific parameter.

Significance level: $* p<0.05$. 


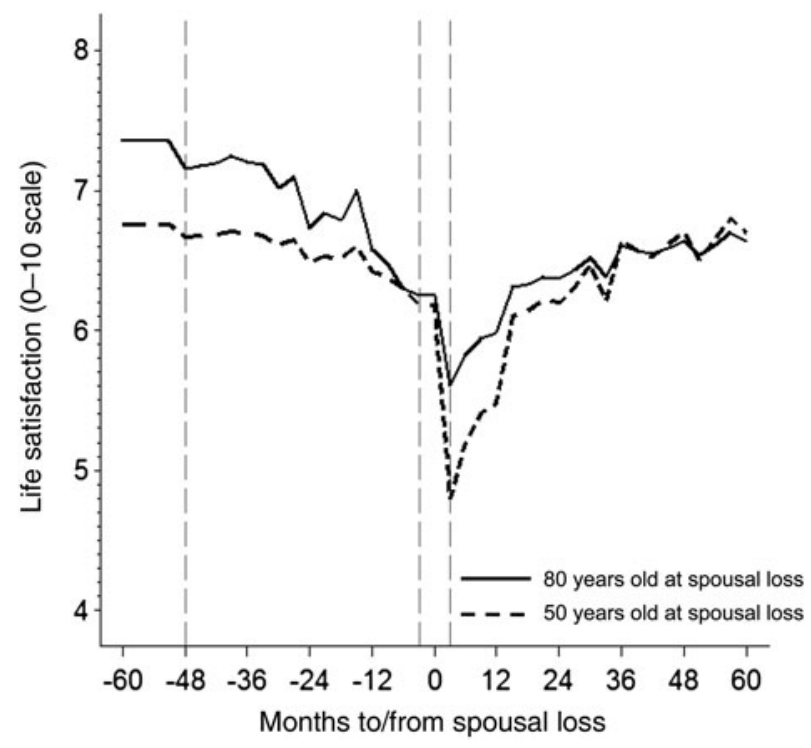

Figure 3. Illustration of the moderating role of age for change in life satisfaction in relation to spousal loss. Older age at spousal loss was associated with an increased likelihood of experiencing stronger life satisfaction declines preceding spousal loss (anticipation) and less steep declines surrounding spousal loss (reaction), whereas younger age at spousal loss was associated with maintenance of life satisfaction prior to spousal loss (anticipation), steeper declines surrounding spousal loss (reaction) and quicker recovery in the years thereafter (adaptation).

with, but also experienced stronger declines in life satisfaction preceding spousal loss (anticipation), whereas younger participants were more likely to experience stronger declines in life satisfaction in the months immediately surrounding spousal loss (reaction), but were more likely to recover in the years thereafter (adaptation).

\section{Longevity following spousal loss}

In a final model, we examined whether level, anticipation, reaction and adaptation were associated with post-loss longevity. We outputted the factor scores for each individual from the model in Table 3 and used those estimated factor scores as predictors in a Cox regression model of mortality risk, controlling for socio-demographics, and social and health resources. Results from Table 5 indicate that pre-spousal loss levels, reaction and adaptation were each associated with longevity. Higher levels of life satisfaction prior to spousal loss, less steep declines in life satisfaction in the months surrounding spousal loss and better adaptation were each associated with an increased likelihood of longevity following spousal loss. 
T A B LE 5. Likelihood of longevity in the years following spousal loss as a function of level, anticipation, reaction and adaptation of life satisfaction

\begin{tabular}{|c|c|c|}
\hline & Hazard ratio & $95 \% \mathrm{CI}$ \\
\hline Intercept & $0.84^{*}$ & $0.77,0.92$ \\
\hline Anticipation & 0.87 & $0.76,1.01$ \\
\hline Reaction & $0.84 *$ & $0.74,0.96$ \\
\hline Adaptation & $0.79 *$ & $0.68,0.92$ \\
\hline Age & $1.08^{*}$ & $1.07,1.09$ \\
\hline Women & $0.45^{*}$ & $0.35,0.57$ \\
\hline Years of education & 0.98 & $0.92,1.05$ \\
\hline Social participation & $0.70^{*}$ & $0.5^{1}, 0.95$ \\
\hline Disability status: individual & 1.13 & $0.90,1.4^{2}$ \\
\hline Disability status: partner & $0.78 *$ & $0.62,0.97$ \\
\hline \multicolumn{3}{|l|}{ Model fit statistics: } \\
\hline Degrees of freedom & \multirow{2}{*}{\multicolumn{2}{|c|}{$\begin{array}{c}10 \\
282.81\end{array}$}} \\
\hline$\chi^{2}$ & & \\
\hline
\end{tabular}

Notes: $\mathrm{N}=1,224$ with 324 recorded deaths in the post-spousal loss observation period. CI: confidence interval.

Significance level: $* p<0.05$.

The parameter estimates in Table 5 are interpreted in regards to how each one-unit increase in the factor of interest is associated with mortality risk. For example, the parameter estimate for reaction was 0.84 , each onepoint less steep change (decline) in life satisfaction surrounding spousal loss from the mean of -1.09 (e.g. reaction estimate $=-0.09)$ was associated with a 16 per cent decreased likelihood of mortality. Finally, each one unit higher level in adaptation (e.g. adaptation estimate $=2.47$ ), signifying better or quicker recovery, was associated with a 21 per cent decreased likelihood of mortality. Figure 4 illustrates the expected differences in mortality risk between individuals who exhibited more-extensive adaptation (solid line; lower likelihood for mortality following spousal loss) and individuals who exhibited less-extensive adaptation (dashed line; higher likelihood for mortality following spousal loss). Additional factors that were related to decreased mortality risk were younger age, being a woman, social participation and partner disability.

\section{Discussion}

The objective was to examine (a) how life satisfaction changes with the experience of spousal loss; (b) whether socio-demographic factors and social and health resources moderate spousal loss-related changes in life satisfaction; and (c) whether extent of anticipation, reaction and adaptation to spousal loss are associated with mortality. We observed that changes in life satisfaction 


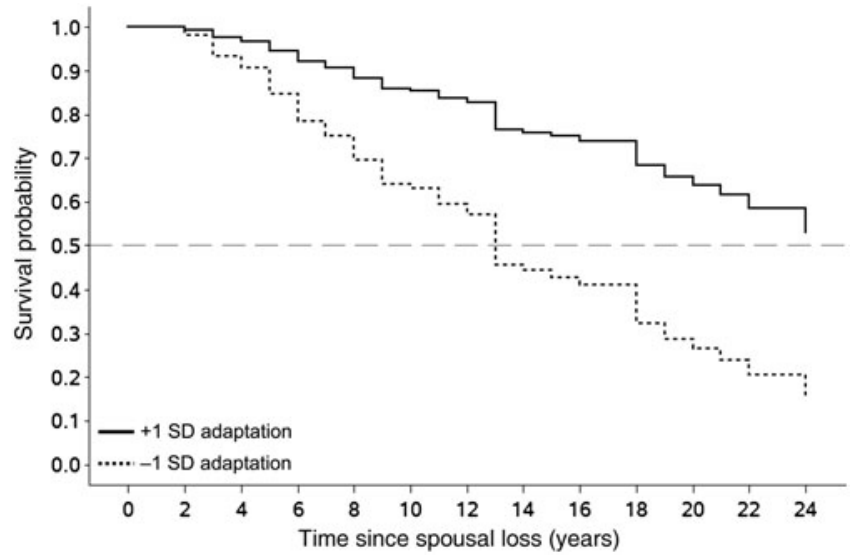

Figure 4. Illustration of the predictive effects of adaptation for survival following spousal loss. Adaptation refers to changes in life satisfaction in the months and years following spousal loss and whether life satisfaction levels are able to recover. More-extensive adaptation following spousal loss was associated with increased likelihood of survival in the years following spousal loss.

Note: SD: standard deviation.

in relation to spousal loss were characterised by a multi-stage pattern. On average, life satisfaction began to decline two and a half years preceding spousal loss (anticipation), steeply dropped during the six months surrounding spousal loss (reaction), with individuals' life satisfaction recovering, but not returning back to pre-loss levels (adaptation). We also found substantial heterogeneity in the extent of changes in life satisfaction. Older adults were less likely to report declines in life satisfaction in the months surrounding spousal loss (reaction), whereas younger age was associated with better recovery following spousal loss (adaptation). Better health, partner disability (indicative of possible care-giving role prior to spousal loss) and greater social participation were additionally associated with better adaptation following spousal loss. In a final step, we found that higher levels of life satisfaction five years prior to, less steep declines surrounding spousal loss (reaction) and better adaptation in the five years following were each associated with increased longevity. Our discussion focuses on the interrelatedness of the time-course through which life satisfaction changes with spousal loss, factors that moderate between-person differences and pathways through which life satisfaction influences longevity following spousal loss.

\section{Change in life satisfaction with spousal loss}

Our aim was to provide an interpretation of the theories on spousal loss and bereavement by modelling change in life satisfaction using three-month 
intervals to decipher the specific time-course that life satisfaction may follow when experiencing spousal loss, anticipation, reaction and adaptation. For reaction, our findings are similar to previous research showing that spousal loss typically results in substantial declines in life satisfaction (Lee and DeMaris 2007; Lucas et al. 2003; Ong, Fuller-Rowell and Bonanno 2010; Wiest et al. forthcoming). For adaptation, we observed that, on average, individuals recovered, but their life satisfaction did not reach the levels reported five years prior to spousal loss. Our findings are similar to previous research showing adaptation to spousal loss, within panel surveys, may take up to eight years (Burke, Shrout and Bolger 2007; Lucas et al. 2003; Wiest et al. forthcoming).

A novel contribution of our study to the larger context of the hedonic treadmill model and how life satisfaction changes as a function of major life events is that individuals may anticipate the incidence of an event. Anticipation of a major life event is characterised by changes in functioning preceding the event (could be months or years) and not just in the months surrounding and years following. Previous conceptual models on spousal loss and bereavement have discussed possible anticipatory changes, but have been vague in when this may begin. Kastenbaum and Costa (1977) discussed that anticipatory grief may begin years leading up to death of a loved one. Our focus was to model directly anticipation that has previously been theorised, and go above and beyond previous research that has solely focused on the reaction and adaptation stages (Lucas et al. 2003; Wiest et al. forthcoming). To move in this direction, we used multi-phase latent basis growth models and modelled change in life satisfaction over threemonth intervals (as opposed to annual intervals). We were able to provide evidence to suggest pre-emptive (anticipatory) changes in life satisfaction around two and a half years prior to spousal loss, with a more substantial drop in life satisfaction in the months surrounding spousal loss. We note that we had to a priori specify the parameters of our model for anticipation and that there are large between-person differences as to when this period may begin. Anticipation can either be adaptive (i.e. proactive self-regulation, bracing oneself) or maladaptive (passive depleted resources before loss even happens). Stronger declines in life satisfaction prior to spousal loss were associated with less steep declines in life satisfaction as a result of spousal loss (reaction) and better adaptation or recovery of life satisfaction following spousal loss.

In accordance with the line of reasoning that considers anticipation of major life events being an active process, the Motivational Theory of Lifespan Development (Heckhausen, Wrosch and Schulz 2010) discusses that as a developmental deadline is approaching or, in this case, a major life event, individuals may engage in various strategies to optimise development 
leading up to and/or following the event. As discussed in the Introduction, an anticipatory strategy may serve this optimising function. Anticipation may be a proactive process that involves the re-directing of one's resources to manage stressful circumstances more effectively and may serve an adaptive purpose following spousal loss through less reaction and thus easier recovery (Heckhausen, Wrosch and Schulz 2010; Wrosch, Amir and Miller 2011). In the case of spousal loss, substantial declines in life satisfaction leading up to spousal loss (anticipation) may protect an individual against further declines surrounding spousal loss (reaction) and thereafter (adaptation). Our empirical results are in line with these hypotheses; we found that stronger declines preceding spousal loss was associated with better recovery/adaptation following spousal loss and this was mediated via less strong reactive declines in life satisfaction in the months surrounding spousal loss.

This study is only an initial step in the direction of broadening our view of developmental change in relation to major life events by incorporating and directly modelling an anticipatory period and its implications for later recovery. It is upon future research to evaluate further whether anticipatory changes are salient in other major life events, such as chronic illness and its functional implications. For example, previous research has shown that although life satisfaction shows substantial changes surrounding disability, the data and results suggest that disability may be foreshadowed by decreases in life satisfaction in the years preceding the event (Lucas 2007 a). Direct modelling of anticipatory changes in life satisfaction preceding major life events and using more fine-grained time intervals (e.g. monthly versus yearly) will allow researchers to examine the course of life satisfaction (and other domains) change in relation to major life events more thoroughly.

\section{Individual differences in life satisfaction change with spousal loss}

Similar to previous conceptual work and empirical reports on resilience to significant life adversity (Boerner, Wortman and Bonanno 2005; Bonanno 2004; Wortman and Silver 1989), we found that there were large betweenperson differences in the extent to which life satisfaction changed in relation to spousal loss. This was in line with our expectations that individuals may follow different paths towards resilience to and recovery from spousal loss, with most individuals displaying substantial declines (Infurna and Luthar in press; Netuveli et al. 2008; Stone, Evandrou and Falkingham 2013). To address this, we examined whether social and health resources and socio-demographic factors moderated such changes. The age of the participant moderated the life satisfaction change during anticipation, 


\section{Frank J. Infurna et al.}

reaction and adaptation. First, individuals who were older experienced steeper anticipatory declines in life satisfaction preceding spousal loss. One interpretation is that at higher ages, the death of a spouse/partner may be drawn out or expected, resulting in more gradual life satisfaction declines in the years leading up to spousal loss (Bonanno and Kaltman 1999). Second, younger age at the time of spousal loss, on average, was associated with steeper declines in life satisfaction in the months surrounding spousal loss. Greater life satisfaction declines with spousal loss in younger ages may be the result of not having a model for mastering the loss, of the fact that plans for the future with one's spouse can no longer be realised and, in the case of having young children, the difficulty of raising the children with one parent can be significant (Carr et al. 2001). Lastly, younger age was associated with better adaptation or quicker recovery following spousal loss. Individuals in young adulthood and mid-life may have more resources to draw upon to promote life satisfaction, have a more-extended future life perspective, and may therefore bounce back more quickly following spousal loss. We note that the experience of spousal loss in young adulthood, mid-life and old age is likely to be qualitatively different. As shown in Figure 3, there may also be initial level differences in life satisfaction between participants who were older and younger at the time of spousal loss.

We observed that better individual health, poorer partner health and greater social participation each moderated life satisfaction change during the adaptation stage. First, individuals who were disabled were less likely to experience recovery of life satisfaction following spousal loss. This could be a result of their self-regulation system already being at its limits and not having the resources to recover from life satisfaction declines with spousal loss (Charles 2010; Infurna, Gerstorf and Ram 2013; Lucas $2007 b)$. Second, partner disability was linked to better adaptation or quicker recovery following spousal loss. Partner disability may be a proxy for the surviving spouse being involved in care-giving-related tasks that may constrain and undermine emotion regulation capacities (Charles 2010), and bereavement may operate as a relief (Schulz et al. 2003). Third, greater social participation prior to spousal loss is an important resource individuals can draw upon to recover from spousal loss in terms of life satisfaction levels returning back to previous levels more quickly (Isherwood, King and Luszcz 2012 ; Zautra et al. 2008). Social participation may operate through various pathways, including cognitive appraisal, coping strategies and health behaviours. Individuals who are more embedded in their social network may be better able to recover from spousal loss through decreasing feelings of social loneliness that can help alleviate and compensate for loss of a spouse (Stroebe et al. 1996). Social participation 
may also operate via having the necessary coping strategies more readily available to buffer against the impact of the stressful life event and move forward in terms of finding a sense of meaning and purpose in life (Bonanno et al. 2007). Furthermore, our measure of social participation included sport activity and this may help individuals maintain their health and social interactions in the face of spousal loss, leading to better life satisfaction (Shahar et al. 2001).

Based on previous empirical evidence (Carr 2004; Lee and DeMaris 2007; Naess, Blekesaune and Jakobsson 2015; Williams 2003), we expected that gender would moderate changes in life satisfaction before and after spousal loss. More specifically, we hypothesised that women would show greater declines in life satisfaction during the time surrounding spousal loss (reaction), but would have the ability to bounce back or recover more quickly (adaptation). However, we did not find evidence that gender moderated changes in life satisfaction. Differences with the prior literature include the large adult lifespan sample, with spousal loss possibly being more detrimental in different stages of the lifespan. For example, older men may show stronger declines in wellbeing following spousal loss due to being less socially integrated. Second, our measure of life satisfaction is representative of cognitive-evaluative components of wellbeing, whereas previous research largely focused on affective components, such as depressive symptoms. There may be differences in the extent to which men and women report depressive symptoms in the context of spousal loss. Lastly, the nature of our analyses was at the more fine-grained time-scale whereas previous research examined mean-level change across fewer assessments (i.e. two or three time assessments).

\section{Mortality following spousal loss}

Our objective was to assess whether one's life satisfaction in the context of spousal loss has mortality implications. Reporting higher levels of life satisfaction, less steep reactive declines surrounding spousal loss and one's ability to adapt were each associated with longevity. Our findings are consistent with previous research from longitudinal surveys that have observed higher levels of life satisfaction may operate as a protective resource against mortality and be indicative of better overall health (Carstensen et al. 2011; Danner, Snowdon and Friesen 2001; Wiest et al. 2011; Zhang et al. 2009). Levels of life satisfaction prior to spousal loss may be linked to longevity through psycho-social functioning and better overall health. First, feeling greater joy over life relates to perceiving that one's actions, behaviours and efforts can shape life circumstances to attain desirable outcomes (Infurna et al. 201 1; Lyubomirsky et al. 2005). Second, higher levels 
of overall life satisfaction are protective against declines in health through partaking in more health-promoting behaviours and buffering against the negative effects of stress on biological functioning (Pressman and Cohen 2005). Focusing on the reaction stage, the maintenance of one's life satisfaction, despite spousal loss, was protective against mortality and may be indicative of resilience in the face of this potentially traumatic event (Mancini, Bonanno and Clark 2011). Too steep declines of life satisfaction after spousal loss may lead to declines in one's engagement and frequency of partaking in activities that sustain one's subjective wellbeing and overall health (Lyubomirsky and Layous 2013). Furthermore, too steep declines may negatively impact one's biological systemic integrity (e.g. broken heart syndrome; Wittstein et al. 2005), leading to increased likelihood of morbidity and mortality (Steptoe and Kivimäki 2012).

Similar to previous research, we observed that individuals who were able to adapt to or recover from spousal loss attained greater longevity (Wiest et al. forthcoming). Remaining at low levels of life satisfaction for an extended period of time may result in long-term dysfunction. Adaptation may be linked to longevity through engaging with one's social network, health behaviours and compensatory strategies. First, quicker recovery following spousal loss may be a proxy for individuals utilising their social network resources to buffer against the negative impact of spousal loss (Antonucci 2001; Berkman et al. 2000). Second, spousal loss can result in declines in health-promoting behaviours and deterioration of nutritional status (Shahar et al. 2001; Wilcox et al. 2003); one's ability for life satisfaction to recover following spousal loss can enable individuals to maintain participation in health-promoting behaviours and better cardiovascular and immune system functioning (Pressman and Cohen 2005; Steptoe, Wardle and Marmot 2005; Wrosch and Schulz 2008). Similarly, positive affect and life satisfaction may be associated with one's ability to engage in adaptive goal (dis)engagement strategies following spousal loss, leading to increased likelihood of longevity (Haase, Poulin and Heckhausen 2012; Wrosch, Schulz and Heckhausen 2004). We were not able to test the specific mechanisms involved in how life satisfaction is associated with longevity following spousal loss. Future studies are needed involving both panel surveys and sub-groups who experienced widowhood to evaluate the proposed mechanisms underlying such associations.

\section{Limitations and outlook}

We note several limitations of our study. First, we acknowledge that there are a myriad of other potential moderators, both in terms of personality and social and health resources, that we were unable to examine due to 
non-availability of data. For example, previous work has shown that higher levels of perceived control and emotional support are associated with more positive life satisfaction in the years following bereavement (Aneshensel, Botticello and Yamamoto-Mitani 2004). Also, developmental heuristics of optimised goals choice and effective goal engagement and disengagement, as well as purpose and meaning in life and personality traits, may help individuals to anticipate and adapt to widowhood (Boyce and Wood 2011; Heckhausen, Wrosch and Schulz 2010; King and Hicks 2009). In a similar vein, financial resources, such as a high(er) income and labour force participation, as well as supportive social relations can potentially help individuals be resilient to spousal loss. The lack of financial resources and supportive social relationships can impose additional stressors and complicate adaptation to spousal loss. Second, we do not have a sufficiently large number of respondents with cause of death information (SOEP did not collect cause of death information prior to 2009; see Infurna et al. 2014). It is likely that cause of death for spouses differed by age, gender and education, possibly leading to differences in the stages of change in life satisfaction with spousal loss. Future research thus should examine whether cause of death of spouse and care-giving characteristics and burden has implications for the life satisfaction and survival of the spouse. Third, there are limitations in our statistical models and pattern of observations in life satisfaction. In particular, we modelled change in life satisfaction based on three-month intervals in that each person was not measured every three months and we do not have data in the three 'missing' observations between each yearly assessment. Fourth, we also imposed where the start and end of each stage was and that each person was required to follow the same (non-parametric) functional form within a stage (e.g. we did not test multiple-group models based on age, gender and education differences). Additional work and data are needed to understand if and how the timing of transitions between, length and pattern of change of each phase may differ across individuals. Fifth, an additional route to extend our statistical models further would be by articulating and testing specific non-linear functions of change (e.g. exponential; see Wiest $e t$ al. forthcoming) rather than the freely estimated form used in our study. This would require more precise articulation of what the patterns of change look like in each stage, what equilibrium is and the appropriate time-scale that these patterns emerge (see Grimm, Ram and Hamagami 2011). Lastly, research examining life satisfaction change in relation to major life events has largely used a single-item measure of life satisfaction. Other components of wellbeing, including positive affect and negative affect, may show a differential pattern, with stronger changes in the time surrounding the event (reaction) and a quicker return back to previous levels following the event (adaptation). 
In sum, spousal loss results in substantial declines in life satisfaction that can be characterised by anticipation, reaction and adaptation, with large betweenperson differences in the extent of change experiences. Intriguingly, anticipation was found to buffer the reaction to spousal loss and thus benefit long-term adaptation. Older adults are more likely than adults in young adulthood and mid-life to experience greater declines in life satisfaction prior to spousal loss, but less steep declines in the months surrounding spousal loss, and younger persons adapt more quickly to this major life event. Social participation is associated with better adaptation in the years following spousal loss. Furthermore, our study showed that life satisfaction levels prior to, as well as reaction and adaptation to spousal loss, are each associated with longevity. Future research should focus on (additional) personality differences in self-regulatory capacities and social resources that may moderate anticipatory, reactive and adaptation changes associated with major life events and the pathways through which changes in life satisfaction are associated with longevity.

\section{Acknowledgements}

Denis Gerstorf and Nilam Ram gratefully acknowledge the support provided by NIA (RC1-AGo35645, R2 1-AGo32379, R2 1-AGo331 o9), NICHD (Ro1-HDo76994, R24HDo41025); the National Center for Advancing Translational Sciences (UL1TRooo 127), the DIW Berlin (German Institute for Economic Research) and the Social Science Research Institute at the Pennsylvania State University. Denis Gerstorf gratefully acknowledges the support provided by the German Research Foundation (DFG, GE 1896/3-1). Additional support was provided by Gert G. Wagner's fellowship from the Max Planck Society. The content is solely the responsibility of the authors and does not necessarily represent the official views of the funding agencies.

\section{References}

Adler, N.E., Boyce, T., Chesney, M.A., Cohen, S., Folkman, S., Kahn, R. L. and Syme, S. L. 1994. Socioeconomic status and health: the challenge of the gradient. American Psychologist, 49, 1, 15-24.

Aldao, A. 2013. The future of emotion regulation research: capturing context. Perspectives on Psychological Science, 8, 2, 155-72.

Allison, P. D. 1995. Survival Analysis Using the SAS(R) System: A Practical Guide. SAS Institute, Cary, North Carolina.

Aneshensel, C. S., Botticello, A. L. and Yamamoto-Mitani, N. 2004. When caregiving ends: the course of depressive symptoms after bereavement. Journal of Health and Social Behavior, 45, 4, 422-40.

Antonucci, T. C. 2001. Social relations: an examination of social networks and social support, and sense of control. In Birren, J.E. (ed.), Handbook of the Psychology of Aging. Fifth edition, Academic Press, San Diego, California, 427-453. 
Baltes, P. B. and Nesselroade, J. R. 1979. History and rationale of longitudinal research. In Nesselroade, J. R. and Baltes, P. B. (eds), Longitudinal Research in the Study of Behavior and Development. Academic Press, New York, 1-39.

Berkman, L. F., Glass, T. A., Brisette, I. and Seeman, T. E. 200o. From social integration to health: Durkheim in the new millennium. Social Science $\mathcal{E} \mathcal{O}^{\mathrm{N}}$ Medicine, 51, 6 , $843-57$.

Bisconti, T. L., Bergeman, C. S. and Boker, S. M. 2006. Social support as a predictor of variability: an examination of the adjustment trajectories of recent widows. Psychology and Aging, 2 1, 3, 590-9.

Boerner, K. and Heckhausen, J. 2003. To have and have not: adaptive bereavement by transforming mental ties to the deceased. Death Studies, 27, 3, 199-226.

Boerner, K., Wortman, C. B. and Bonanno, G. A. 2005. Resilient or at risk? A 4-year study of older adults who initially showed high or low distress following conjugal loss. Journals of Gerontology: Psychological Sciences, 6oB, 2, P67-73.

Bonanno, G. A. 2004. Loss, trauma, and human resilience: have we underestimated the human capacity to thrive after extremely adverse events? American Psychologist, 59, 1, 20-8.

Bonanno, G. A., Galea, S., Bucciarelli, A. and Vlhaov, D. 2007. What predicts psychological resilience after disaster? The role of demographics, resources, and life stress. Journal of Consulting and Clinical Psychology, 75, 5, 671-82.

Bonanno, G. A. and Kaltman, S. 1999. Toward an integrative perspective on bereavement. Psychological Bulletin, 125, 6, 760-76.

Bonanno, G. A., Wortman, C. B., Lehman, D. R., Tweed, R. G., Haring, M., Sonnega, J., Carr, D. and Nesse, R. M. 2002. Resilience to loss and chronic grief: a prospective study from preloss to 18 -months postloss. Journal of Personality and Social Psychology, 83, $5,115^{\mathrm{O}-64}$.

Boyce, C. J. and Wood, A. 2011 . Personality prior to disability determines adaptation: agreeable individuals recover loss life satisfaction faster and more completely. Psychological Science, 22, 1 1, 1397-402.

Brickman, P. and Campbell, D. T. 1971. Hedonic relativism and planning the good society. In Appley, M.H. (ed.), Adaptation Level Theory: A Symposium. Academic Press, New York, 287-302.

Burke, C. T., Shrout, P. E. and Bolger, N. 2007. Individual differences in adjustment to spousal loss: a nonlinear mixed model analysis. International Journal of Behavioral Development, 31, 4, 405-15.

Carr, D. S. 2004. Gender, preloss marital dependence, and older adults' adjustment to widowhood. Journal of Marriage and Family, 66, 1, 220-35.

Carr, D., House, J. S., Kessler, R. C., Nesse, R. M., Sonnega, J. and Wortman, C. 2000. Marital quality and psychological adjustment to widowhood among older adults: a longitudinal analysis. Journals of Gerontology: Social Sciences, 55B, 4, S197-207.

Carr., D., House, J. S., Wortman, C., Nesse, R. and Kessler, R. C. 2001. Psychological adjustment to sudden and anticipated spousal loss among older widowed persons. Journals of Gerontology: Social Sciences, 56B, $4, \mathrm{~S}_{237-48 .}$

Carr, D. and Utz, R. 2002. Late-life widowhood in the United States: new directions in research and theory. Ageing International, 27, 1, 65-88.

Carstensen, L. L., Turan, B., Scheibe, S., Ram, N., Ersner-Hershfield, H., SamanezLarkin, G. R., Brooks, K. P. and Nesselroade, J. R. 2011 . Emotional experience improves with age: evidence based on over 10 years of experience sampling. Psychology and Aging, 26, 1, 21-33.

Charles, S. T. 2010. Strength and vulnerability integration: a model of emotional life satisfaction across adulthood. Psychological Bulletin, 136, 6, 1068-91. 
Cox, P. R. 1972. Regression models and life tables. Journal of the Royal Statistical Society Series B (Methodological), 34, 3, 187-220.

Danner, D. D., Snowdon, D. A. and Friesen, W. V. 2001. Positive emotions in early life and longevity: findings from the Nun Study. Journal of Personality and Social Psychology, 8o, 5, 804-13.

Diener, E., Lucas, R. E. and Scollon, C. N. 20o6. Beyond the hedonic treadmill: revising the adaptation theory of life satisfaction. American Psychologist, 61, 4, 305-14.

Elliott, D. B. and Simmons, T. 2011 . Marital events of Americans: 2009. American Community Survey Reports, ACS-1 3, US Census Bureau, Washington DC.

Elwert, F. and Christakis, N. A. 2008. The effect of widowhood on mortality by the causes of death of both spouses. American Journal of Public Health, 98, 1 1, 2092-8.

Floyd, F. J., Seltzer, M. M., Greenberg, J. S. and Song, J. 2013. Parental bereavement during mid-to-later life: pre- and postbereavement functioning and intrapersonal resources for coping. Psychology and Aging, 28, 2, 402-13.

Fortunato, C. K., Gatzke-Kopp, L. M. and Ram, N. 2013. Associations between respiratory sinus arrhythmia reactivity and internalizing and externalizing symptoms are emotion specific. Cognitive, Affective, $\mathcal{E}$ Behavioral Neuroscience, 13, 2, 238-51.

Frederick, S. and Loewenstein, G. 1999. Hedonic adaptation. In Kahneman, D., Diener, E. and Schwarz, N. (eds), Life Satisfaction: The Foundations of Hedonic Psychology. Sage, New York, 302-29.

Frijters, P., Johnston, D. W. and Shields, M. A. 2011 . Life satisfaction dynamics with quarterly life event data. Scandinavian Journal of Economics, 113, 1, 190-211.

Fujita, F. and Diener, E. 2005. Life satisfaction set point: stability and change. Journal of Personality and Social Psychology, 88, $1,158-64$.

Gaugler, J. E., Pot, A. M. and Zarit, S. H. 2007. Long-term adaptation to institutionalization to dementia caregivers. The Gerontologist, 47, 6, 730-40.

Gerstorf, D., Ram, N., Estabrook, R., Schupp, J., Wagner, G. G. and Lindenberger, U. 2008. Life satisfaction shows terminal decline in old age: longitudinal evidence from the German Socio-Economic Panel Study (SOEP). Developmental Psychology, 44, 4, $1148-59$.

Gerstorf, D., Smith, J. and Baltes, P. B. 2006. A systemic-wholistic approach to differential aging: longitudinal findings from the Berlin Aging Study. Psychology and Aging, 2 1, 4, 645-663.

Glaser, B. G. and Strauss, A. L. 1968. Time for Dying. Aldine, Chicago.

Grimm, K. J., Ram, N. and Hamagami, F. 2011 . Nonlinear growth curves in developmental research. Child Development, 82, 5, 1357-71.

Haase, C. M., Heckhausen, J. and Wrosch, C. 2013 . Developmental regulation across the life span: toward a new synthesis. Developmental Psychology, 49, 5, 964-72.

Haase, C. M., Poulin, M. and Heckhausen, J. 201 2. Happiness as a motivator: positive affect predicts primary control striving for career and educational goals. Personality and Social Psychology Bulletin, 38, 8, 1093-104.

Headey, B., Muffels, R. and Wagner, G. G. 2010. Long-running German panel survey shows that personal and economic choices, not just genes, matter for happiness. Proceedings of the Academy of Sciences of the United States of America, 107, 42, 17922-6.

Heckhausen, J., Wrosch, C. and Schulz, R. 2010. A motivational theory of life-span development. Psychological Review, 117, 1, 332-6o.

Holmes, T. H. and Rahe, R. H. 1967. The social readjustment rating scale. Journal of Psychosomatic Research, 11, 2, 21 1 -8.

Infurna, F. J., Gerstorf, D. and Ram, N. 2013. The nature and correlates of change in depressive symptoms with cancer diagnosis: reaction and adaptation. Psychology and Aging, 28, 2, 386-401. 
Infurna, F. J., Gerstorf, D., Ram, N., Schupp, J. and Wagner, G. G. 2011 . Long-term antecedents and outcomes of perceived control. Psychology and Aging, 26, 3, 559-75.

Infurna, F. J., Gerstorf, D., Ram, N., Sprangers, M. A. G., Schupp, J. and Wagner, G. G. 2014. Linking concurrent self-reports and retrospective informant-reports about the last year of life: a prevailing picture of life satisfaction decline. Journals of Gerontology: Psychological and Social Sciences, 69B, 5, 695-709.

Infurna, F.J. and Luthar, S. S. Resilience to major life stressors is not as common as thought. Perspectives on Psychological Science, in press.

Infurna, F. J., Ram, N. and Gerstorf, D. 2013. Level and change in perceived control predict 19-year mortality: findings from the Americans' Changing Lives Study. Developmental Psychology, 49, 10, 1833-47.

Isherwood, L. M., King, D. S. and Luszcz, M. A. 201 2. A longitudinal analysis of social engagement in late-life widowhood. International Journal of Aging and Human Development, 74, 3, $211-29$.

Jopp, D. and Smith, J. 20o6. Resources and life-management strategies as determinants of successful aging: on the protective effect of selection, optimization, and compensation. Psychology and Aging, 2 1, 2, 253-65.

Kastenbaum, R. and Costa, P. T. 1977. Psychological perspectives on death. Annual Review of Psychology, 28, 1, 225-49.

King, L. A. and Hicks, J. A. 2oog. Detecting and constructing meaning in life events. The Journal of Positive Psychology, 4, 5, 317-30.

Kroh, M., Pischner, R., Spiess, M. and Wagner, G. G. 2008. On the treatment of nonoriginal sample members in the German Household Panel Study (SOEP): tracing the weighting. Methoden-Daten-Analysen, 2, 2, 179-98.

Lachman, M. E. and Weaver, S. L. 1998. The sense of control as a moderator of social class differences in health and well-being. Journal of Personality and Social Psychology, 74, $3,763-73$.

Lee, G. R. and DeMaris, A. 2007. Widowhood, gender, and depression: a longitudinal analysis. Research on Aging, 29, 1, 56-72.

Lichtenstein, P., Gatz, M., Pedersen, N. L., Berg, S. and McClearn, G. E. 1996. A cotwin-control study of response to widowhood. Journals of Gerontology: Psychological Sciences, 51B, 5 , P279-89.

Little, R. J.A. and Rubin, D. B. 1987. Statistical analysis with missing data. New York, NY: Wiley.

Lucas, R. E. 2007a. Adaptation and the set-point model of subjective well-being: does happiness change after major life events? Current Directions in Psychological Science, 16, 2, $75^{-9}$.

Lucas, R. E. $2007 b$. Long-term disability is associated with lasting changes in subjective well-being: evidence from two nationally representative longitudinal studies. Journal of Personality and Social Psychology, 92, 4, 71 7-30.

Lucas, R. E., Clark, A. E., Georgellis, Y. and Diener, E. 2003. Reexamining adaptation and the set point model of happiness: reactions to changes in marital status. Journal of Personality and Social Psychology, 84, 3, 527-39.

Lyubomirsky, S., King, L. and Diener, E. 2005. The benefits of frequent positive affect: does happiness lead to success?. Psychological Bulletin, 131, 6, 803-55.

Lyubomirsky, S. and Layous, K. 2013. How do simple positive activities increase well-being?. Current Directions in Psychological Science, 22, 1, 57-62.

Mancini, A. D., Bonanno, G. A. and Clark, A. E. 2011. Stepping off the hedonic treadmill: individual differences in response to major life events. Journal of Individual Differences, 32, 3, 144-52. 


\section{Frank J. Infurna et al.}

McArdle, J.J. 20og. Latent variable modeling of differences and changes with longitudinal data. Annual Review of Psychology, 6o, 1, 577-605.

Mroczek, D. K. and Spiro, A., III 2007. Personality change influences mortality in older men. Psychological Science, 18, 5, 371-6.

Muthén, L. K. and Muthén, B. O. 2012. Mplus User's Guide (7th ed.). Los Angeles, CA: Author.

Myrskylä, M. and Margolis, R. 2014. Happiness: before and after the kids. Demography, 51, 5, 1843-66.

Naess, S., Blekesaune, M. and Jakobsson, N. 2015. Marital transitions and life satisfaction: evidence from longitudinal data from Norway. Acta Sociologica, 58, 1, 63-78.

Netuveli, G., Wiggins, R. D., Montgomery, S. M., Hildon, Z. and Blane, D. 2008. Mental health and resilience at older ages: bouncing back after adversity in the British Household Panel Survey. Jourmal of Epidemiology and Community Health, 62, 1 1, 987-91.

Neugarten, B. L. and Hagestad, G. O. 1976. Age and the life course. In Binstock, R. E. and Shanas, E. (eds), Handbook of Aging and Social Sciences. Van Nostrand Reinhold, New York. 35-61.

Noll, H.-H., Habich, R. and Schupp, J. 2008. Datenreport 20o8-Ein Sozialbericht für die Bundesrepublik Deutschland. Statistisches Bundesamt, Bundeszentrale für politische Bildung, Wissenschaftszentrum Berlin für Sozialforschung (WZB), Berlin.

Ong, A. D., Fuller-Rowell, T. E. and Bonanno, G. A. 2010. Prospective predictors of positive emotions following spousal loss. Psychology and Aging, 25, 3, 653-6o.

Parslow, R. A., Jorm, A. F., Christensen, H. and Mackinnon, A. 2006. An instrument to measure engagement in life: factor analysis and associations with sociodemographic, health, and cognition measures. Gerontology, 52, 3, 188-98.

Pressman, S. D. and Cohen, S. 2005. Does positive affect influence health? Psychological Bulletin, 131, 6, 925-71.

Ram, N. and Grimm, K. 2007. Using simple and complex growth models to articulate developmental change: matching theory to method. International Journal of Behavioral Development, 31, 4, 303-16.

Roelfs, D. J., Shor, E., Curreli, M., Clemow, L., Burg, M. M. and Schwartz, J. E. 2012. Widowhood and mortality: a meta-analysis and meta-regression. Demography, 49, 2, $575^{-606 .}$

Schulz, R. and Beach, S. R. 1999. Caregiving as a risk factor for mortality: the Caregiver Health Effects Study. Journal of the American Medical Association, 282, 23, $2215^{-9}$.

Schulz, R., Belle, S. H., Czaja, S. J., McGinnis, K. A., Stevens, A. and Zhang, S. 2004. Long-term care placement of dementia patients and caregiver health and wellbeing. Journal of American Medical Association, 292, 8, 961-67.

Schulz, R., Mendelsohn, A. B., Haley, W. E., Mahoney, D., Allen, R. S., Zhang, S., Thompson, L. and Belle, S. H. 2003. End-of-life care and the effects of bereavement on family caregivers of persons with dementia. New England Journal of Medicine, 349, 20, 1936-42.

Shahar, D. R., Schultz, R., Shahar, A. and Wing, R. R. 2001. The effect of widowhood on weight change, dietary intake, and eating behavior in the elderly population. Journal of Aging and Health, 13, 2, 186-99.

Singer, J. D. and Willett, J. B. 2003. Applied Longitudinal Data Analysis: Modeling Change and Event Occurrence. New York, NY: Oxford University Press.

Sobel, M. E. 1982. Asymptotic confidence intervals for indirect effects in structural equation models. Sociological Methodology, 13, 1982, 290-312.

Steptoe, A. and Kivimäki, M. 2012 . Stress and cardiovascular disease. Nature Reviews Cardiology, 9, 6, 360-70. 
Steptoe, A., Wardle, J. and Marmot, M. 2005. Positive affect and health-related neuroendocrine, cardiovascular, and inflammatory processes. Proceedings of the Academy of Sciences of the United States of America, 102, 18, 6508-12.

Stevens, N. 1995. Gender and adaptation to widowhood in later life. Ageing E Society, $15,1,37-5^{8}$.

Stone, J., Evandrou, M. and Falkingham, J. 2013. The transition to living alone and psychological distress in later life. Age and Ageing, 42, 3, 366-72.

Stroebe, M., Schut, H. and Stroebe, W. 2007. Health outcomes of bereavement. Lancet, 370, 9603, 1960-73.

Stroebe, W., Stroebe, M., Abakoumkin, G. and Schut, H. 1996. The role of loneliness and social support in adjustment to loss: a test of attachment versus stress theory. Journal of Personality and Social Psychology, 7o, 6, 1241-9.

Stroebe, W., Zech, E., Stroebe, M. S. and Abakoumkin, G. 2005. Does social support help in bereavement? Journal of Social and Clinical Psychology, 24, 7, 1030-50.

Uglanova, E. A. and Staudinger, U. M. 2013. Zooming in on life events: is hedonic adaptation sensitive to the temporal distance from the event. Social Indicators Research, $111,1,265-86$.

Wade, T. J. and Pevalin, D. J. 2004. Marital transitions and mental health. Journal of Health and Social Behavior, 45, 2, 155-70.

Wagner, G. G., Frick, J. R. and Schupp, J. 2007. Enhancing the power of household panel studies: the case of the German Socio-Economic Panel Study (SOEP). Schmollers Jahrbuch, $1217,139-69$.

Wiest, M., Huxhold, O., Wurm, S., Tesch-Römer, C. and Schüz, B. Individual differences in adaptation to critical life events predict mortality. Forthcoming.

Wiest, M., Schüz, B., Webster, N. and Wurm, S. 2011 . Subjective well-being and mortality revisited: differential effects of cognitive and emotional facets of well-being on mortality. Health Psychology, 3o, 6, 728-35.

Wilcox, S., Evenson, K. R., Aragaki, A., Wassertheil-Smoller, S., Mouton, C. P. and Loevinger, B. L. 2003. The effects of widowhood on physical and mental health, health behaviors, and health outcomes: the Women's Health Initiative. Health Psychology, 22, 5, 513-22.

Williams, K. 2003. Has the future of marriage arrived? A contemporary examination of gender, marriage, and psychological well-being. Journal of Health and Social Behavior, 44, 4, 470-87.

Williams, K. 2004. The transition to widowhood and the social regulation of health: consequences for health and health risk behavior. Journals of Gerontology: Social Sciences, 59B, 6, S343-9.

Wittstein, L.S., Thiemann, D. R., Lima, J.A. C., Baughman, K. T., Schulman, S. P., Gerstenblith, G., Wu, K. C., Rade, J.J., Bivalacqua, T.J., Champion, H. C. 2005. Neurohumoral features of myocardial stunning due to sudden emotional stress. New England Journal of Medicine, 352, 6, 539-48.

Wortman, C. B. and Boerner, K. 2007. Reactions to the death of a loved one: Myths of coping versus scientific evidence. In Friedman H. S. and Silver R. C. (eds), Foundations of Health Psychology, New York, NY: Oxford. 28 $5^{-324}$.

Wortman, C. B. and Silver, R. C. 1989. The myths of coping with loss. Journal of Consulting and Clinical Psychology, 57, 3, 349-57.

Wrosch, C., Amir, E. and Miller, G. E. 201 1. Goal adjustment capacities, coping, and subjective well-being: the sample case of caregiving for a family member with mental illness. Journal of Personality and Social Psychology, 10o, 5, 934-46.

Wrosch, C. and Schulz, R. 2008. Health-engagement control strategies and 2-year changes in older adults' physical health. Psychological Science, 19, 6, 537-41. 


\section{Frank J. Infurna et al.}

Wrosch, C., Schulz, R. and Heckhausen, J. 2004. Health stresses and depressive symptomatology in the elderly: a control-process approach. Current Directions in Psychological Science, 13, 1, 17-20.

Zautra, A.J., Hall, J. S., Murray, K. E. and the Resilience Solutions Group 2008. Resilience: a new integrative approach to health and mental health research. Health Psychology Review, 2, 1, 41-64.

Zhang, J-P., Kahana, B., Kahana, E., Hu, B. and Pozuelo, L. 20o9. Joint modeling of longitudinal changes in depressive symptoms and mortality in a sample of community-dwelling elderly people. Psychosomatic Medicine, 71, 7, 704-14.

Accepted 4 December 20I5; first published online I I April 20 I 6

Address for correspondence:

Frank J. Infurna,

Arizona State University,

Department of Psychology, 95o S. McAllister Ave.,

Tempe, AZ 85287 , USA

E-mail: Frank.Infurna@asu.edu 